\title{
Reduced Brain Serotonin Activity Disrupts Prepulse Inhibition of the Acoustic Startle Reflex: Effects of 5,7-dihydroxytryptamine and $p$-chlorophenylalanine
}

Paul J. Fletcher, D.Phil., Zoë F. Selhi, H.B.Sc., Arezou Azampanah, M.Sc., and Terrence L. Sills, Ph.D.

These experiments examined the impact of extensive depletions of forebrain 5-hydroxytryptamine (5-HT; serotonin) levels on prepulse inhibition (PPI) of the acoustic startle reflex in rats. In Experiment 1, injection of the neurotoxin 5,7-dihydroxytryptamine (5,7-DHT) into the dorsal and median raphe nuclei disrupted PPI. This deficit was observed beginning 2 days after lesioning and was still apparent 8 weeks later. Basal startle reactivity was not altered. The $5-\mathrm{HT}_{1 \mathrm{~A}}$ receptor agonist $8-\mathrm{OH}-\mathrm{DPAT}(0.1 \mathrm{mg} /$ $\mathrm{kg}$ ) and the dopamine receptor agonist apomorphine $(1 \mathrm{mg} /$ $\mathrm{kg}$ ) also disrupted PPI; the effect of 8-OH-DPAT, but not apomorphine, was potentiated in 5-HT-depleted rats. Basal startle reactivity was enhanced by 8-OH-DPAT in sham-lesioned rats but not in 5,7-DHT-lesioned rats. In
Experiment 2, a second method for depleting 5-HT was used. The tryptophan hydroxylase inhibitor p-chlorophenylalanine (PCPA) also disrupted PPI without altering basal startle reactivity. Again, 8-OH-DPAT disrupted PPI in control animals; this effect was not altered in PCPA-treated rats but the increase in basal startle reactivity induced by $8-O H-D P A T$ was not observed in PCPA-treated rats. Taken together with the results of previous experiments involving drugs that enhance 5-HT neurotransmission it appears that both increases and decreases in 5-HT activity disrupt PPI.

[Neuropsychopharmacology 24:399-409, 2001] (C) 2001 American College of Neuropsychopharmacology. Published by Elsevier Science Inc.
KEY WORDS: Prepulse inhibition; Startle reflex; Serotonin; 5,7-dihydroxytryptamine; 8-OH-DPAT; $\mathrm{p}$-chlorophenylalanine

Prepulse inhibition (PPI) refers to the normal reduction of a startle response when a weak stimulus (prepulse) precedes a startle-eliciting stimulus within a very short time period (Graham 1975; Hoffman and Ison 1980).

From the Section of Biopsychology, Centre for Addiction and Mental Health, Toronto, Ontario, Canada (PJF, ZFS, AA, TLS); and the Departments of Psychiatry and Psychology, University of Toronto, Toronto, Canada (PJF).

Address correspondence to: P.J. Fletcher, Section of Biopsychology, Centre for Addiction and Mental Health, Clarke Division, 250 College St., Toronto, Canada M5T 1R8. Tel.:(416) 535-8501, ext. 4058; Fax:(416) 979-6942; E-mail:fletcher@psych.utoronto.ca
PPI is one operational measure of sensorimotor gating, the ability of an organism to properly inhibit sensory information (Graham 1975; Swerdlow et al. 1991). Schizophrenic patients exhibit deficits in PPI and lack the ability to filter irrelevant stimuli (Braff et al. 1978, 1992). Such abnormalities have been suggested to reflect sensory flooding and cognitive fragmentation, features that are characteristic of these patients (McGhie and Chapman 1961). Furthermore, PPI has become an attractive animal model for exploring the neural substrates underlying schizophrenia, since both humans and animals are tested using near-identical stimulus parameters (Geyer and Braff, 1987; Geyer et al. 1990).

Although the circuitry involved in mediating the acoustic startle reflex is relatively simple (Davis et al. 
1982; Koch 1999), the activity of this system can be altered at a variety of neuroanatomical and neurochemical levels to affect the PPI of this reflex. Studies involving rats indicate that multiple neurotransmitter systems may modulate PPI; these systems include dopamine, glutamate, acetylcholine, GABA, and 5-hydroxytryptamine (5-HT; serotonin) (see Koch 1999 for review). In regard to serotonergic influences on PPI a number of studies have shown that drug-induced increases in serotonergic neurotransmission disrupt PPI. The list of drugs that disrupt PPI via stimulation of 5-HT function include the 5-HT releasers fenfluramine, p-chloroamphetamine, and 3,4-methylenedioxy-methamphetamine (MDMA) (Kehne et al. 1996). More selective 5-HT receptor agonists that disrupt PPI are the $5-\mathrm{HT}_{1 \mathrm{~A}}$ receptor agonist 8-OH-DPAT (Rigdon and Weatherspoon 1992; Sipes and Geyer, 1995), the mixed 5-HT ${ }_{1 \mathrm{~A} / 1 \mathrm{~B}}$ receptor agonist RU24969, the non-selective $5-\mathrm{HT}_{2}$ receptor agonist $\mathrm{DOI}$, and the $5-\mathrm{HT}_{2 \mathrm{C}}$ receptor agonist m-chlorophenylpiperazine (Sipes and Geyer 1994, 1995, 1997). Thus, PPI can be reduced by increasing 5-HT neurotransmission through multiple 5-HT receptor sub-types.

In contrast to the well-studied effects of increased function the impact of reducing 5-HT function on PPI has not been thoroughly investigated. Systemic administration of the 5- $\mathrm{HT}_{1 \mathrm{~A}}$ agonist 8-OH-DPAT reduces PPI (Rigdon and Weatherspoon 1992). Receptors of the $5-\mathrm{HT}_{1 \mathrm{~A}}$ subtype are located post-synaptically as well as on serotonergic cell bodies in the dorsal and median raphe nuclei (Pazos and Palacios 1985; Pompeiano et al. 1992). These somatodendritic receptors function as autoreceptors; $5-\mathrm{HT}_{1 \mathrm{~A}}$ receptor stimulation inhibits the activity of raphe 5-HT neurons (Sprouse and Aghajanian 1987) leading to reduced release of 5-HT in terminal regions (Hjorth and Magnusson 1988; Hjorth and Sharp 1991). Therefore it is reasonable to hypothesize that the effect of 8-OH-DPAT to reduce PPI may involve diminished 5-HT function. In support of this view Sipes and Geyer (1995) reported that 8-OH-DPAT infusions into either the dorsal raphe or the median raphe nuclei reduced PPI. These deficits were reversed by WAY 100, 135 , a selective $5-\mathrm{HT}_{1 \mathrm{~A}}$ antagonist, and were not attributable to a general effect on startle reactivity. In light of these findings, the main goal of the present study was to determine the impact of longer term depletion of brain 5-HT levels on PPI. To this end the effects of destroying brain 5-HT neurons on PPI were investigated by injecting the specific 5-HT neurotoxin 5,7-dihydroxytryptamine (5,7-DHT) into both the dorsal and median raphe nuclei. The impact of such lesions on the disruptive effects of systemically administered 8-OH-DPAT was also examined. For comparative purposes the effects of the dopamine receptor agonist, apomorphine, were also examined since this drug has been widely used as a pharmacological means of disrupting PPI.
Additionally, we examined the effects of depletion of 5-HT, induced by the tryptophan hydroxylase inhibitor $p$-chlorophenylalanine (PCPA) (Koe and Weissman 1966) on the expression of PPI, as well as on the ability of 8-OH-DPAT to disrupt PPI. Thus, these studies provide a comparison of the effects of three quite different methods of reducing 5-HT activity on PPI.

\section{METHODS}

\section{Subjects}

Male Sprague-Dawley rats (Charles River, St. Constant, Quebec) weighing between 250-300 g at the time of surgery were used. Animals were housed in clear plastic cages on a $12 \mathrm{hr}$ light/dark schedule (lights on at 08:00 h) and at a temperature of $22 \pm 2^{\circ} \mathrm{C}$. Rats had ad libitum access to standard Purina lab chow and water. All animals were handled within 4 days of arrival and daily thereafter. All treatments and tests were carried out during the light phase. Experimental procedures and manipulations conformed to the guidelines laid down by the Canadian Council on Animal Care, and were approved by the Animal Care Committee at the Centre for Addiction and Mental Health.

\section{Apparatus}

Testing occurred in four startle chambers (SR-LAB, San Diego Instruments, San Diego, CA). Each startle chamber was enclosed within a $37.5 \times 40.0 \times 57.5 \mathrm{~cm}$ isolated cabinet, and contained a ventilated Plexiglas cylinder $8.2 \mathrm{~cm}$ in diameter, which was positioned upon a $12.5 \times 25.5 \mathrm{~cm}$ Plexiglas platform. Acoustic noise bursts were presented via a loudspeaker mounted $24 \mathrm{~cm}$ above the cylinder. A piezoelectric accelerometer unit was attached below the cylinder to transduce the vibrations from within the cylinder into signals that were rectified and recorded by an IBM-PC compatible computer and interface assembly. In every chamber, sound levels were measured and calibrated with a sound meter (Radio Shack, model no. 33-2055). Response sensitivities were calibrated using the SR-LAB Startle Calibration System. The startle response was measured every $1 \mathrm{msec}$ for a $250 \mathrm{msec}$ period from the onset of the startle stimulus. Startle amplitude, the dependent measure, was defined as the average of the $2501 \mathrm{msec}$ readings. In addition the peak startle amplitude within this $250 \mathrm{msec}$ period was also recorded.

\section{Experiment 1: Effects of 5,7-dihydroxytryptamine Lesions of the Raphe Nuclei}

Rats were anaesthetized with sodium pentobarbital (Somnotol; $45-50 \mathrm{mg} / \mathrm{kg}$, IP), after pre-treatment with $10 \mathrm{mg}$ / $\mathrm{kg}$ desipramine (IP), and placed in a stereotaxic frame. A 
30-gauge stainless steel needle was lowered into first the median raphe (MR) nucleus. Using an infusion pump, 4 $\mu \mathrm{g}$ 5,7-DHT (5,7-dihydroxytryptamine creatinine sulphate; Sigma-Aldrich Canada, Oakville, Ontario), free base, dissolved in $1 \%$ ascorbic acid was infused into the target nucleus over a period of $4 \mathrm{~min}$. The needle was left in place for another $2 \mathrm{~min}$, then raised to the dorsal raphe (DR) nucleus. Another $4 \mu \mathrm{g}$ of 5,7-DHT was infused into this nucleus for $4 \mathrm{~min}$, and the needle was left in place for 2 min. Nine rats received combined 5,7-DHT lesions. Eight sham-lesioned control animals were subject to identical treatment, but with infusions of $1 \%$ ascorbic acid only. The co-ordinates relative to interaural zero were: $\mathrm{AP}$ $+1.2 \mathrm{~mm}, \mathrm{~L} 0 \mathrm{~mm}, \mathrm{~V}+4.4 \mathrm{~mm}$ (DR) or $+2.0 \mathrm{~mm}$ (MR).

\section{PPI Testing}

Animals underwent PPI testing on days 2, 7, 14, 21, and 30 after surgery. A test session began by placing the rat in the startle chamber with background white noise set at $65 \mathrm{~dB}$. After receiving a $10 \mathrm{~min}$ acclimation period, subjects were presented with three trials of a $120 \mathrm{~dB}$ stimulus; responses to this stimulus were subsequently discarded. Each subject was then presented with 9 iterations of 8 types of trials (total 72 trials): no pulse $(0 \mathrm{~dB})$, a startle pulse (110 dB, $40 \mathrm{msec}$ broadband burst), three prepulse intensities $(70,75,80 \mathrm{~dB}, 20 \mathrm{msec}$ broadband burst), and each of the 3 prepulse intensities delivered $100 \mathrm{msec}$ prior to a startle pulse. The presentation of trial type was randomized within each of the nine iterations, and the average intertrial interval was 15 seconds (range 10-20), randomized across all 72 trials. During all PPI testing sessions, animals with lesions and sham-lesioned controls were counter-balanced across startle chambers. On days 33, 37, and 40 after surgery rats were tested for PPI as described above following injections of saline, 100 $\mu \mathrm{g} / \mathrm{kg}$ 8-OH-DPAT (8-hydroxy-2(di- $n$-propylamino)tetralin hydrobromide; Research Biochemicals International, Natick, MA), or $1 \mathrm{mg} / \mathrm{kg}$ apomorphine hydrochloride (Sigma) injected SC, in a volume of $1 \mathrm{ml} / \mathrm{kg}, 10$ min prior to being placed in startle chambers. Drugs were administered in a semi-randomised order with approximately equal numbers of rats in each group receiving each drug on the 3 test days.

On days 45,49 , and 56 after surgery rats were again tested for PPI, in the absence of any injections, as described above.

\section{Experiment 2: Effects of PCPA}

Sixteen rats were used. Eight animals were treated with $150 \mathrm{mg} / \mathrm{kg} p$-chlorophenylalanine (PCPA) ethyl ester injected IP, once daily for 3 days. The other eight rats received vehicle injections of distilled water only. On days 4 and 6 after PCPA or water treatment rats were tested for PPI following injections (SC) of $100 \mu \mathrm{g} / \mathrm{kg}$
8-OH-DPAT or saline. Rats received each injection in a counterbalanced order $10 \mathrm{~min}$ before being placed in the startle chambers. PPI was measured as described for Experiment 1.

Rats treated with PCPA show a depletion of 5-HT which recovers with de novo synthesis of tryptophan hydroxylase (Koe and Weissman 1966). To determine the influence of PCPA on brain 5-HT levels at the time of PPI testing, 6 naive rats received injections of PCPA, and 6 received injections of distilled water as described above.

\section{Neurochemical Analysis}

Approximately 1 week after completion of testing, 5,7DHT-lesioned rats and their controls were killed by decapitation and their brains were removed. PCPAtreated rats and their controls were sacrificed 6 days post-treatment. The hippocampus and striatum was immediately dissected, and subsequently frozen over dryice and stored at a temperature of $-70^{\circ} \mathrm{C}$. The extent and specificity of the 5-HT depletion were determined by measuring, using HPLC with electrochemical detection, the levels of 5-HT, dopamine, noradrenaline (NA), and their metabolites following extraction in $0.1 \mathrm{~N}$ perchloric acid containing $2 \mu \mathrm{M}$ sodium bisulphite as an antioxidant. The analytical system consisted of a Waters 600 Mutlisolvent Pump (Milford, MA), an Hichrom (Reading, UK) $250 \times 4.6 \mathrm{~mm}$ column with ODS2 $5 \mu \mathrm{m}$ packing material, an ESA (Chelmsford, MA) Coulochem 5100A detector with 5020 Guard Cell and a 5011 Analytical Cell, a TSP AS3000 refrigerated autosampler, and a Spectra Physics (Mountain View, CA) SP4290 Integrator. The mobile phase comprised $0.822 \mathrm{M}$ acetic acid, $0.094 \mathrm{M}$ sodium acetate, $6 \%$ methanol, $0.8 \mathrm{mM}$ octane sulphonate, and $0.124 \mathrm{mM}$ EDTA in purified distilled water filtered through a $0.22 \mu \mathrm{m}$ nylon filter.

\section{Data Analysis}

All data were analyzed with Statistica (StatSoft Inc., Tulsa, OK ). For startle and PPI two measures of startle amplitude were used; the mean startle amplitude over $250 \mathrm{~ms}$, and the peak startle response recorded during this period. For the former measure the amount of PPI was expressed as the percent decrease in startle response caused by presentation of the prepulse, according to the formula [100 $\times$ (mean startle amplitude on pulse alone trials - mean startle amplitude on prepulse+pulse trials) / mean startle amplitude on pulse-alone trials)]. For measures based on peak startle values these values were used in the above formula in place of mean startle amplitudes. Increases in sensorimotor gating are reflected by higher percent PPI values. Data were analyzed using analysis of variance (ANOVA) with specific post hoc comparisons made using Fisher's least significant difference (LSD) tests. The criterion for significance was $p<.05$. 
In all experiments the profile of results was comparable using both mean startle amplitudes (averaged over $250 \mathrm{~ms}$ ) and peak startle amplitudes (over the 250 $\mathrm{ms}$ period). The data reported here are based on mean startle amplitudes. Peak startle amplitude results are not shown except for the first phase of Experiment 1 to indicate the comparability of data based on these two measures of startle amplitude.

\section{RESULTS}

\section{Neurochemistry}

As shown in Table 1 intra-raphe administration of 5,7DHT resulted in greater than $90 \%$ reduction in $5-\mathrm{HT}$ and 5-HIAA levels in the hippocampus and striatum. Treatment with PCPA also induced comparable reductions in 5-HT and 5-HIAA in a separate group of rats run in parallel with those involved in the PPI study.

\section{Effects of 5-7-DHT on PPI and Startle}

The effects of 5,7-DHT treatment on PPI on days 2, 7, 14,21 , and 30 post-surgery were analyzed using a three-way analysis of variance with Lesion as a between-subjects factor, and Prepulse Stimulus Intensity and Day as within-subjects factors. This analysis showed that \%PPI increased as a function of increasing prepulse stimulus intensity $[\mathrm{F}(2,30)=80.94 p<$ .001] and was significantly reduced by the Lesion $[\mathrm{F} 1,15=13.98, p<.002]$. A significant interaction between the effects of the Lesion and Prepulse Stimulus Intensity was also found $[\mathrm{F}(2,30)=8.63, p<.001]$. Neither the main effect of Day nor any of the interaction terms involving Day was statistically significant. Therefore, PPI scores were collapsed across days, and these data are illustrated in Figure 1a. A two-way analysis of variance revealed significant main effects of Lesion $[\mathrm{F}(1,15)=13.98, p<.002]$, Prepulse Intensity $[\mathrm{F}(2,30)=80.98, p<.001]$ and a significant interaction $[\mathrm{F}(2,30)=8.63, p<.001]$. However, post-hoc tests confirmed that 5,7-DHT lesioned rats exhibited significantly lower PPI scores compared to sham-lesioned animals at all three intensities. Using peak startle amplitudes the mean percentage $( \pm$ SEM) PPI scores observed in sham-lesioned rats at 70, 75 and $85 \mathrm{~dB}$ prepulse intensities were $35.0( \pm 5.2), 54.8( \pm 5.8)$, and $71.1( \pm 3.9)$, respectively. The corresponding values for 5,7-DHT-lesioned rats were $22.2( \pm 4.3), 32.2( \pm 5.8)$, and $40.1( \pm 6.8)$. Analysis of variance revealed significant main effects of Prepulse Stimulus Intensity $[\mathrm{F}(2,30)=53.20, p<.0001]$ and Lesion $[\mathrm{F}(1,15)=$ $10.16, p<.01]$ and an interaction between these two factors $[F(2,30)=6.08, p<.01]$. Again, post-hoc tests confirmed that 5,7-DHT lesioned rats exhibited significantly lower PPI scores compared to sham-lesioned animals at all three intensities.

In contrast to the disruptive effect on PPI, 5-HT depletion did not alter basal startle reactivity, measured as the mean startle amplitude in response to the $110 \mathrm{~dB}$ pulse. Thus, the main effects of Day, Lesion and their interaction were all non-significant [all F's $<1.1$ ]. Average startle scores collapsed across days are shown in Figure $1 \mathrm{~B}\left(\mathrm{t}_{15}=0.85, p>.4\right)$. Similarly, using peak startle amplitudes the sham and 5,7-DHT lesioned groups were not significantly different: sham, 938 ( \pm 139$)$; 5,7DHT, $953( \pm 116),\left(t_{15}=0.93, p>.4\right)$.

The effects of the 5,7-DHT lesion post-drug testing, on days 45,49 , and 56 were similar to those observed prior to drug testing. The three-way analysis of variance revealed that overall PPI was increased as a function of prepulse intensity $[\mathrm{F}(2,30=109.7, p<.001]$, and that 5 -HT depletion significantly reduced PPI $[\mathrm{F}(1,15)=6.43$, $p<.03]$. Since the main effect of days and all of the interaction terms were not significant (all F's $<1.7, p>$.2) data were collapsed across days Analysis of these data, shown in Figure $1 \mathrm{C}$ revealed significant main effects of Lesion $[\mathrm{F}(1,15)=6.43, p<.02]$ and Prepulse Stimulus Intensity $[\mathrm{F}(2,30)=109.01, p<.001]$. As shown in Fig-

Table 1. Levels of 5-HT, 5-HIAA, DA and NA in Striatum and Hippocampus Following 5,7-DHT or PCPA Treatment

\begin{tabular}{|c|c|c|c|c|c|c|}
\hline & \multicolumn{3}{|c|}{ Striatum } & \multicolumn{3}{|c|}{ Hippocampus } \\
\hline & $5-\mathrm{HT}$ & 5-HIAA & DA & 5-HT & 5-HIAA & NA \\
\hline Sham & $0.581(0.03)$ & $0.849(0.04)$ & $11.657(0.46)$ & $0.466(0.01)$ & $0.4049(0.02)$ & $0.4599(0.028)$ \\
\hline 5,7-DHT & $0.0468(0.029)$ & $0.0562(0.037)$ & $10.699(0.330)$ & $0.024(0.006)$ & $0.036(0.01)$ & $0.381(0.03)$ \\
\hline Percent of Control & $8^{*}$ & $7^{*}$ & 92 & $5^{*}$ & $9^{*}$ & 83 \\
\hline Veh & $0.6542(0.02)$ & $0.816(0.06)$ & $9.829(0.79)$ & $0.500(0.025)$ & $0.415(0.032)$ & $0.489(0.026)$ \\
\hline PCPA & $0.028(0.002)$ & $0.0024(0.01)$ & $10.55(0.62)$ & $0.017(0.001)$ & $0.009(0.01)$ & $0.357(0.028)$ \\
\hline Percent of Control & $4^{*}$ & $3^{*}$ & 107 & $3^{*}$ & $2^{*}$ & 73 \\
\hline
\end{tabular}

Values represent mean $( \pm$ SEM) tissue levels expressed as ng/mg tissue. Measurements of NA in striatum, and DA in hippocampus were not performed.

${ }^{*} p<.01$ compared to Sham or Veh. 
A
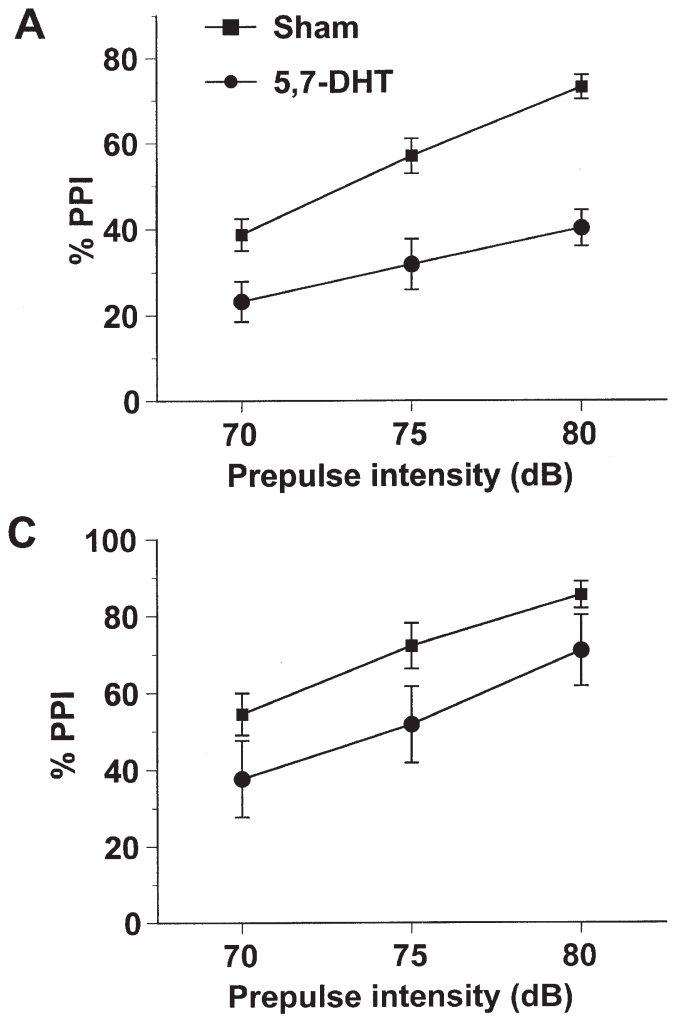

B

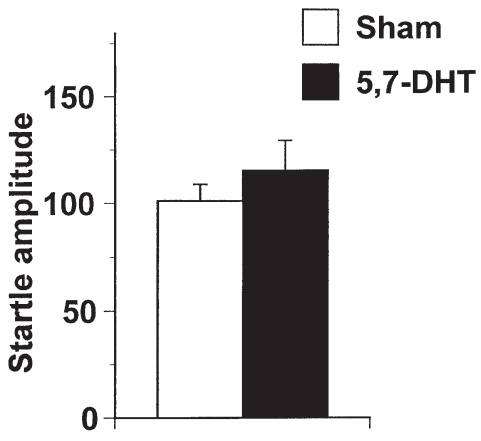

D

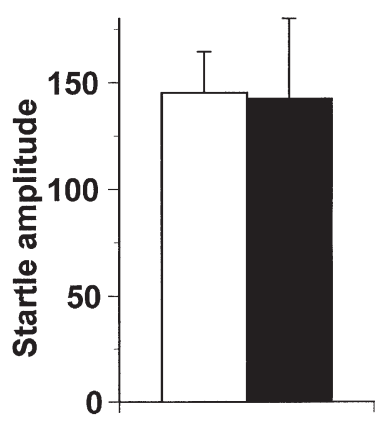

Figure 1. The effects of 5,7-DHT-lesions and sham lesions on (A) percentage PPI of the acoustic startle response at prepulse intensities of 70,75 and $80 \mathrm{~dB}$, and (B) mean startle amplitude to the $110 \mathrm{~dB}$ startle stimulus. Data represent the mean (+SEM) percentage inhibition of the acoustic startle reflex, or of startle amplitude averaged over testing days 2, 7, 14, 21, and 30 (pre-drug testing). See text for statistical details. Panels C and D illustrate \%PPI and startle responses respectively collapsed over days 45, 49, and 56 (post-drug testing). See text for statistical details. In this, and all subsequent figures, data are derived from the mean startle amplitude recorded over a period of $250 \mathrm{~ms}$ beginning at the onset of the startle stimulus.

ure $1 \mathrm{D}$, reactivity to the startle-alone stimulus $(110 \mathrm{~dB})$ was not altered by the lesion $\left(\mathrm{t}_{15}=0.73, p>.1\right)$.

\section{Effects of 8-OH-DPAT and Apomorphine on PPI in Sham and 5,7-DHT Lesioned Rats}

To increase power of the statistical analyses the effects of 8-OH-DPAT and apomorphine were analyzed separately and compared to the same saline control condition. Each analysis consisted of a 2 (sham vs. lesion) $\times 2$ (saline vs. drug) $\times 3$ (prepulse intensity) analysis of variance. The effects of 8-OH-DPAT on PPI in shamand 5,7-DHT lesioned rats are shown in Figure 2. Results of the three-way analysis of variance confirmed that PPI increased with prepulse stimulus intensity $[\mathrm{F}(2,30)=41.89 p<.001]$, that the lesion group had overall reduced PPI $[\mathrm{F}(1,15)=9.47, p<.01]$ and that 8 -OH-DPAT reduced PPI $[\mathrm{F}(1,15)=50.95, p<.001]$. The overall interaction between the three factors was significant $[\mathrm{F}(2,30)=3.7, p<.04]$. Tests of simple interactions showed that significant interactions between 8-OH-DPAT and Lesion occurred at the $75 \mathrm{~dB}[\mathrm{~F}(1,15)=$ $16.01, p<.01]$ and $80 \mathrm{~dB}[\mathrm{~F}(1,15)=5.19, p<.04]$ prepulse intensities. Further post-hoc testing of these interactions confirmed that the disruptive effect of 8-OH-DPAT on PPI was significantly greater in lesioned rats compared to their sham-lesioned controls at 75 and $80 \mathrm{~dB}$. The 8 -OH-DPAT $\times$ Lesion interaction at $70 \mathrm{~dB}$ was not significant $[\mathrm{F}(1,15)=0.85, p>.3]$ presumably because of the trend towards reduced PPI in the 5,7-DHT lesioned rats. Post-hoc tests confirmed that this reduction was not significant, but that the effect of $8-\mathrm{OH}-\mathrm{DPAT}$ was significantly greater in lesioned versus control animals.

As shown in Figure 3 apomorphine also induced an overall disruptive effect on PPI $[\mathrm{F}(1,15)=30.75, p<$ .001]. The three-way interaction approached significance $[\mathrm{F}(2,30)=2.91, p=.069]$. However, tests of Lesion $\times$ apomorphine interactions at each prepulse intensity revealed that these interactions differed significantly across the three prepulse intensities. Thus, at 70 $\mathrm{dB}$ a significant interaction between the lesion condition and apomorphine treatment $[\mathrm{F}(1,15)=11.28, p<$ $.01]$ was found. This interaction occurred because of a reversal of the disruptive effect of apomorphine on PPI in the lesioned rats. At the two other prepulse intensities apomorphine was equally effective in both sham 
$70 \mathrm{~dB}$

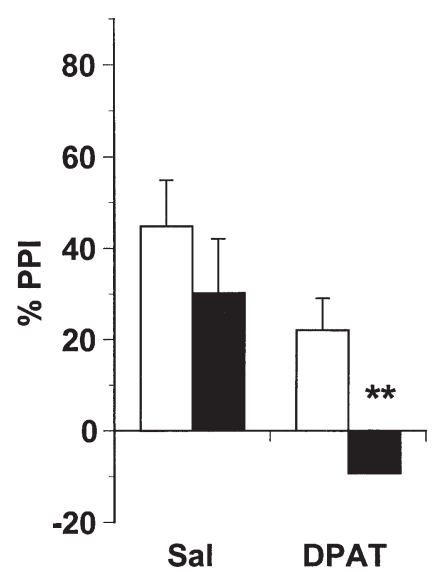

$75 \mathrm{~dB}$

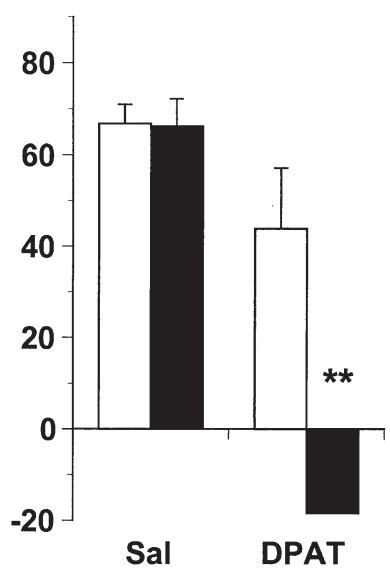

Sham

5,7-DHT

Figure 2. The effects of 8-OH-DPAT $(0.1 \mathrm{mg} / \mathrm{kg})$ or saline on \%PPI in 5,7-DHT-lesioned and sham-lesioned rats at prepulse intensities of 70,75, and $80 \mathrm{~dB}$. Bars represent mean (+SEM) percentage inhibition of the acoustic startle reflex. Error bars not visible are within the boundaries of the column. ${ }^{* *}$ significantly different from Sham-DPAT condition, $p<.01$

and lesioned rats, as shown by the lack of interaction between these two factors $(p>.08)$ in both cases.

\section{Effects of 8-OH-DPAT and Apomorphine on Startle in Sham and 5,7-DHT Lesioned rats}

Figures 5A and 5B illustrate the effects of 8-OH-DPAT and apomorphine on responding to the startle stimulus $(110 \mathrm{~dB})$ alone. For the analysis involving a comparison between 8-OH-DPAT and saline, there was an overall main effect of 8-OH-DPAT $[\mathrm{F}(1,15)=7.27, p<.02]$ and a significant interaction between 8-OH-DPAT and Lesion $[\mathrm{F}(1,15)=5.17, p<.04]$. Post-hoc tests confirmed that 8-OH-DPAT increased startle in shamlesioned rats but not in 5,7-DHT lesioned rats. The lesion alone had no effect on startle responding. Apomorphine failed to alter startle responding in either sham or lesioned animals [all $\mathrm{F}^{\prime} \mathrm{S}<0.5$, not significant].
$70 \mathrm{~dB}$

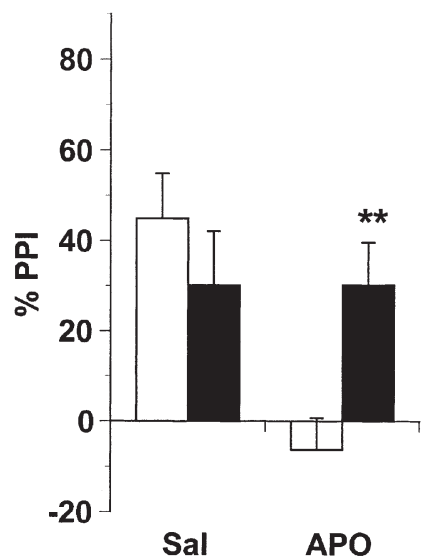

$75 \mathrm{~dB}$

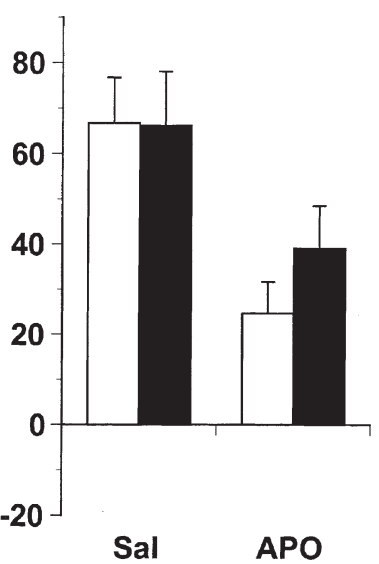

$80 \mathrm{~dB}$

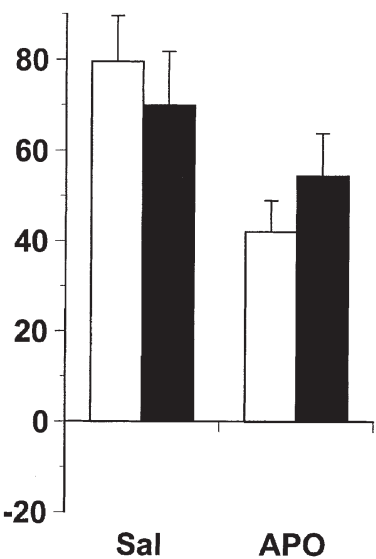

Figure 3. The effects of apomorphine $(1 \mathrm{mg} / \mathrm{kg})$ or saline on $\%$ PPI in 5,7-DHT-lesioned and sham-lesioned rats at prepulse intensities of 70,75 , and $80 \mathrm{~dB}$. Bars represent mean $(+\mathrm{SEM})$ percentage inhibition of the acoustic startle reflex. ${ }^{* *}$ significantly different from Sham-APO condition, $p<.01$. 


\section{Effects of PCPA on PPI and Startle}

The effects of PCPA and 8-OH-DPAT on PPI are shown in Figure 4. An overall three-way ANOVA with PCPA as the between-subjects factor, and 8-OH-DPAT and prepulse stimulus intensity as the within-subjects factors, revealed significant main effects of prepulse stimulus condition, $[\mathrm{F}(2,48)=22.42, p<.001], 8-\mathrm{OH}-\mathrm{DPAT}[\mathrm{F}(1,24)=9.51$, $p<.001]$ and PCPA treatment $[\mathrm{F}(1,24)=4.81, p<.04]$. These results reflect the observations that PPI increased with prepulse intensity, and that both the 8-OH-DPAT and PCPA treatments significantly reduced the level of PPI at all prepulse intensities (Figure 4). The only interaction term to reach significance was that involving the 8-OH-DPAT and PCPA factors $[\mathrm{F}(1,24)=4.89, p<.04]$. Post hoc comparisons based on this interaction confirmed that PCPA treatment and 8-OH-DPAT both reduced PPI, and that PCPA did not modify the effect of 8-OH-DPAT.

To examine the effects of the depletion of serotonin on startle responding following treatment with saline and 8-OH-DPAT (Figure 5C), a two-way analysis of variance was carried out, with PCPA as the between-subjects factor, and 8-OH-DPAT as the within-subjects factor. This analysis revealed a significant main effect of 8-OH-DPAT only $[\mathrm{F}(1,24)=7.59, p<.01]$. Although the main effect of PCPA $[\mathrm{F}(1,24)=1.62, p>.2]$ and the interaction were not significant $[\mathrm{F}(1,24)=1.31, p>.2]$ post-hoc testing indicated that $8-\mathrm{OH}-\mathrm{DPAT}$ increased startle reactivity in vehicle-pretreated rats but not in PCPA-treated rats.

\section{DISCUSSION}

The main finding of this study is that severe depletion of brain 5-HT levels disrupted PPI of the acoustic startle reflex. This disrupted PPI was evident in animals treated either with the serotonin neurotoxin, 5,7-DHT, or with the tryptophan hydroxylase inhibitor PCPA. Both treatments reduced 5-HT and 5-HIAA levels in the striatum and hippocampus by greater than $90 \%$, and disrupted PPI at all 3 prepulse intensities. In contrast to the effect on PPI, neither 5,7-DHT treatment nor PCPA altered basal startle activity, as measured in response to the $110 \mathrm{~dB}$ stimulus. These results are consistent with prior reports that startle reactivity is not altered by either 5,7-DHT (Eison et al. 1986) or PCPA (Davis et al. 1988). Thus, the disruption of PPI induced by both treatments cannot be attributed to any effect on basal startle activity.

A number of pharmacological manipulations, primarily involving drugs that enhance 5-HT neurotransmission, disrupt PPI. Selective activation of $5-\mathrm{HT}_{1 \mathrm{~A}}, 5-\mathrm{HT}_{1 \mathrm{~B}}$, and $5-\mathrm{HT}_{2 \mathrm{~A}}$ receptors alone is seemingly sufficient to disrupt PPI indicating that 5-HT, acting via multiple 5-HT receptor sub-types can disrupt PPI. Selective blockade of 5- $\mathrm{HT}_{1 \mathrm{~A}}$ (Sipes and Geyer 1995), 5- $\mathrm{HT}_{2 \mathrm{~A}}$ (Padich et al. 1996) receptors, non-selective blockade of 5- $\mathrm{HT}_{2}$ receptors (Sipes and Geyer 1994), and deletion of the $5-\mathrm{HT}_{1 \mathrm{~B}}$ receptor (Dulawa et al. 1997) do not alter PPI but clearly prevent the disruptive effects of receptor agonists. Thus, the disruption of PPI observed after 5-HT depletion described in the present report most likely involves a reduction in 5-HT neurotransmission mediated through several receptor sub-types, rather than any single receptor.

The effect of 5,7-DHT to disrupt PPI was quite marked, stable, and long-lasting, being evident up to 8 weeks post-surgery. However, during the course of the experiments examining the effects of 8-OH-DPAT and apomorphine on PPI the 5,7-DHT lesioned rats treated

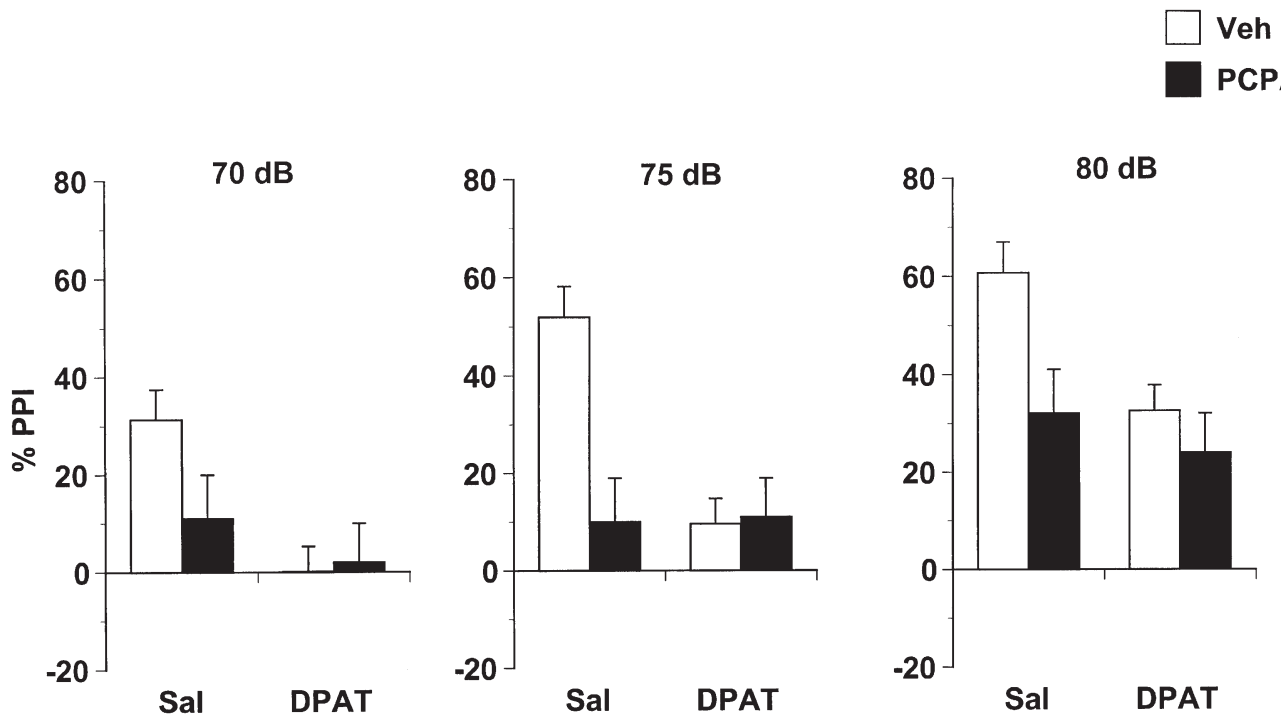

Figure 4. The effects of $0.1 \mathrm{mg} / \mathrm{kg} 8-\mathrm{OH}-\mathrm{DPAT}$ on $\%$ PPI scores in rats pretreated with PCPA $(150 \mathrm{mg} / \mathrm{kg} \times 3) \mathrm{or}$ its vehicle at prepulse intensities of 70,75, and $80 \mathrm{~dB}$. Bars represent mean (+SEM) percentage inhibition of the acoustic startle reflex. 
A

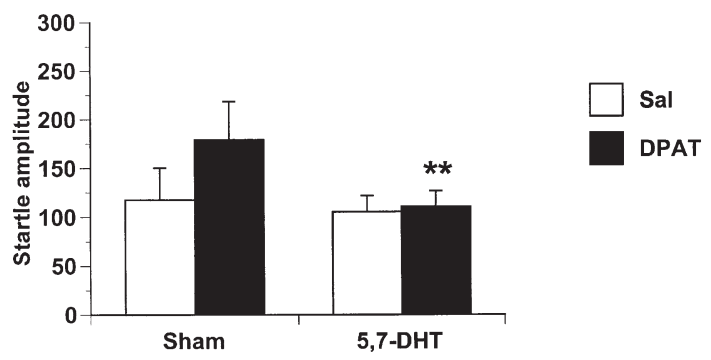

B

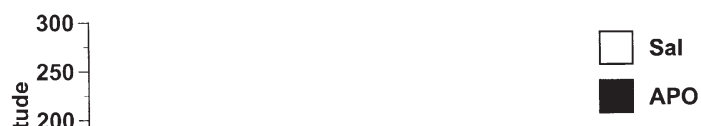

\section{C}

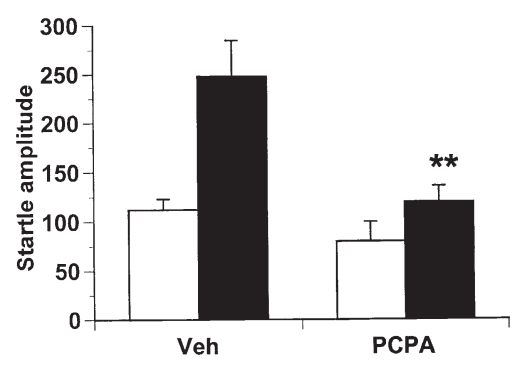

Figure 5. Panels $\mathbf{A}$ and $\mathbf{B}$ illustrate the effects of 8-OH-DPAT $(0.1 \mathrm{mg} / \mathrm{kg})$ and apomorphine $(1 \mathrm{mg} / \mathrm{kg})$, respectively, on mean + SEM startle amplitudes (in response to $110 \mathrm{~dB}$ stimuli) in 5,7-DHT-lesioned and sham-lesioned rats. Panel C shows the effect on startle amplitude of 8-OHDPAT $(0.1 \mathrm{mg} / \mathrm{kg})$ administered to rats pretreated with PCPA $(150 \mathrm{mg} / \mathrm{kg} \times 3)$ or its vehicle. ${ }^{* *} p<.01$ compared to Sham-DPAT condition (A) or Veh-DPAT condition (C).

with saline showed PPI scores that were not significantly different from those of sham-lesioned rats. The reason for this is not clear but cannot be attributed to an altered basal startle reactivity on drug test days since 5-HT depleted rats did not differ from their sham-operated controls on a measure of reactivity to the $110 \mathrm{~dB}$ startle stimulus alone. Nor did this response vary substantially over the entire duration of the experiment. Studies involving lesioning of brain structures or chemical systems always run the risk that emerging compensatory changes in brain function can lead to amelioration of any deficit. Such compensatory changes in brain 5-HT activity and in behavior have previously been reported following 5,7-DHT-induced damage to 5-HT neurons (Azmitia et al. 1978). The development of such compensatory mechanisms seems an unlikely explanation in the present experiments since the ability of 5,7DHT-induced reductions in 5-HT levels to reduce PPI did not change significantly over the time course of the experiment. Indeed, the disruption of PPI that was observed on the last test day (day 56), some 8 weeks after lesioning, was robust and obvious at all three stimulus intensities. Experimental procedures and protocols were similar on all pre-drug, post-drug and drug-testing days with the exception that rats received injections on those days in which 8-OH-DPAT, apomorphine and saline were administered. Since these rats were not habituated to injection procedures prior to beginning these tests it is possible that the stress of the injections may have interacted in some fashion with 5-HT depletion to alter basal PPI in these animals. Despite this seemingly anomalous finding, the pattern of effects induced by 5,7-DHT over the whole duration of the experiment was one of a strong, and generally reliable, attenuation of PPI.

Further support for the notion that reduced 5-HT function disrupts PPI of the acoustic startle reflex derives from the observation that rats treated with PCPA showed the same deficit in PPI. This disruption of PPI was found after saline injections, but unlike the rats treated with 5,7-DHT these PCPA-treated rats had received experience with injections, for administration of PCPA, prior to PPI testing. The results of both experiments clearly show that two different neuropharmacological procedures that deplete central 5-HT levels induce a similar profile of behavioral change, namely a disruption of PPI without an alteration in basal startle reactivity. These findings are also consistent with the disruption of PPI induced by injecting 8-OH-DPAT into the dorsal and median raphe nuclei that leads to acute suppressions of raphe cell firing and 5-HT release in terminal areas (Hjorth and Magnusson 1988; Sprouse and Aghajanian 1987).

In the present experiments we also confirmed the observation that systemic injection of a low dose of 8-OH-DPAT reduces PPI (Rigdon and Weatherspoon 1992; Sipes and Geyer 1995). Both 5,7-DHT and PCPA treatment failed to reverse the effect of 8-OH-DPAT on PPI. In the case of PCPA this is not surprising given the massive impact of PCPA to reduce PPI in its own right. For the 5,7-DHT lesioned rats, as noted above, basal PPI was not disrupted providing a fortuitous opportunity to determine whether chronic 5-HT depletion can ameliorate the deficit in PPI induced by 8-OH-DPAT. However, the results of this experiment indicated that the effect of 8-OH-DPAT was significantly enhanced in 5,7DHT depleted rats. One possible explanation for this enhancement is that it reflects an additive effect of the disruptive effect of 8-OH-DPAT, with a latent or nonexpressed, disruptive effect of the lesion under the saline injection condition. Arguing against this explanation is the finding that apomorphine-induced disruption of PPI was not enhanced in 5,7-DHT treated rats. In fact, at the $70 \mathrm{~dB}$ prepulse intensity the effect of apo- 
morphine was significantly reversed by 5 -HT depletion. An alternative explanation for the enhanced effect of 8-OH-DPAT could be that it reflects an action of 8 -OH-DPAT on post-synaptic $5-\mathrm{HT}_{1 \mathrm{~A}}$ receptors that have been rendered supersensitive by 5-HT depletion. Although such upregulation of $5-\mathrm{HT}_{1 \mathrm{~A}}$ receptor function has not been consistently demonstrated using quantitative autoradiography (e.g. Compan et al. 1998; Hensler et al. 1991), enhanced electrophysiological, behavioral (Lucki 1992), and hormonal (Van der Kar et al. 1998) responses to $5-\mathrm{HT}_{1 \mathrm{~A}}$ agonists occur following 5,7-DHT treatment. In PCPA treated rats the response to 8-OH-DPAT was not enhanced, but because testing of the effects of 8-OH-DPAT occurred within 3 days of ceasing treatment with PCPA, this may not have been sufficient time to allow for the emergence of upregulation of $5-\mathrm{HT}_{1 \mathrm{~A}}$ receptorrelated activity. If this explanation is correct then it indicates that 8-OH-DPAT can disrupt PPI via a postsynaptic receptor mechanism, as well as via an action on inhibitory somatodendritic autoreceptors (Sipes and Geyer 1995).

Manipulation of 5-HT activity modulates the expression of dopamine-mediated neurotransmission and behavior. The interactions between these two systems are complex but, at least under certain circumstances, 5-HT depletion may potentiate dopamine-mediated behavior (see Fletcher et al. 1999 for a more detailed discussion). In this context 5-HT depletion enhances the stimulant effect of apomorphine in an open-field (Drescher et al. 1985). Contrary to this finding in the present experiment 5,7-DHT-lesioned rats showed an attenuation of the disruptive effect of apomorphine on PPI. This result should be viewed with some caution given that the effect was observed at only the lowest prepulse intensity, and that during the course of the apomorphine experiment the usual 5,7-DHT induced reduction in PPI was not apparent. However, the result does not support the view that lowering 5-HT activity potentiates the effects of direct dopamine receptor stimulation at least in terms of PPI.

Examination of the effects of 5,7-DHT, and PCPA, as well as their interactions with 8-OH-DPAT on the acoustic startle response revealed an interesting pattern of results. Despite the marked effects of 5,7-DHT and PCPA to reduce PPI, neither treatment altered responsivity to the startle stimulus alone. In contrast, 8-OH-DPAT significantly elevated the startle response to this stimulus, and this effect was blocked by prior treatment with both 5,7-DHT and PCPA. This blockade of the startle-enhancing response of 8-OH-DPAT by 5-HT depletion strongly suggests that $8-\mathrm{OH}-\mathrm{DPAT}$ increases startle reactivity by inhibiting 5-HT neurotransmission. This conclusion in turn raises the question of why the startle response was not altered by either 5,7-DHT or PCPA, both of which also clearly reduced 5-HT neurotransmission. Interestingly, Davis and Sheard (1976) have shown that the 5-HT depletor $p$-chloroamphetamine (PCA) increased startle reactivity for a period of about $15 \mathrm{hr}$ after injection, but that startle responses subsequently returned to control levels. The treatment dose of PCA used in those experiments induced a depletion of 5-HT that lasted for at least 4 weeks. Davis and Sheard (1976) argued that a critical factor in determining whether reduced 5-HT function enhances startle reactivity relates to the rate of decline of 5-HT levels. Thus, the key factor is not the absolute level of 5-HT, but the rate of decline of 5-HT activity. The present results appear to support this view; an acute, reversible reduction in 5-HT activity, induced by 8-OH-DPAT, is associated with increased startle whereas a sustained depletion of 5-HT induced by 5,7-DHT or PCPA does not alter startle. However, both acute and chronic reductions in 5-HT activity are sufficient to disrupt PPI of the acoustic startle response.

The neuronal circuit involved in the acoustic startle reflex is relatively simple, with the caudal nucleus of the pontine reticular formation ( $\mathrm{PnC}$ ) involved as an important relay between auditory and motor systems (Davis et al. 1982; Yeomans and Frankland 1996). It has been proposed that during PPI of the acoustic startle response, the prepulse engages neuronal systems of the pedunculopontine tegmental nucleus (PPtg) that project to the PnC (Koch 1999; Swerdlow et al. 1992; Swerdlow and Geyer 1993). In turn, the activity of the PPtg is modulated by a complex cortico-limbic-striatal circuitry involving multiple anatomical sites including the medial prefrontal cortex, amygdala, nucleus accumbens, ventral pallidum, septo-hippocampal system, and ventral tegmental area. Altered activity in any of these systems, induced by lesions or drugs has been shown to modulate PPI (reviewed in Koch 1999). In the present studies 5,7-DHT and PCPA would be expected to reduce 5-HT levels throughout the forebrain and so it is not possible to conclude from the present experiments where in this proposed circuitry 5-HT depletion may act to disrupt PPI. However, it is noteworthy that 5-HT neurons innervate all aspects of these cortico-limbicstriatal regions (Azmitia 1978). Future experiments involving anatomically-restricted lesions could be used to determine whether the deleterious effects of 5-HT depletion on PPI result from a focal loss of 5-HT input to any given site, or whether a generalized forebrain deficit is required to disrupt PPI.

The present results, together with those obtained using intra-raphe injections of 8-OH-DPAT, clearly indicate that PPI can be disrupted by manipulations that reduce 5-HT neurotransmission. This finding together with those demonstrating similar effects following 5-HT agonist treatment show that 5-HT does not exert a bidirectional influence on sensorimotor gating. Rather, it appear that disruptions that lead to both hyper- and hypo-functioning 5-HT systems can alter the sensorim- 
otor-gating process as expressed by PPI of the acoustic startle reflex. Such results indicate that the expression of normal PPI may require an optimal level of 5-HT activity and deviations away from this level disrupt sensorimotor gating regardless of the direction of change.

\section{ACKNOWLEDGMENTS}

This work was supported by an operating grant from the Medical Research Council of Canada to PJF and TLS. PJF is a Career Scientist of the Ontario Ministry of Health.

\section{REFERENCES}

Azmitia EC (1978): The serotonin-producing neurons of the midbrain median and dorsal raphe nuclei. In Iversen LL, Iversen SD, Snyder SH (eds), Handbook of Psychopharmacology. New York, Plenum, pp 233-314

Azmitia EC, Buchan AM, Williams JH (1978): Structural and functional restoration by collateral sprouting of hippocampal 5-HT axons. Nature 274:374-376

Braff DL, Grillon C, Geyer MA (1992): Gating and habituation of the startle reflex in schizophrenic patients. Arch Gen Psychiat 49:206-215

Braff DL, Stone C, Callaway E, Geyer MA, Glick ID, Bali L (1978): Prestimulus effects on human startle reflex in normals and schizophrenics. Psychophysiol 14:339-343

Compan V, Segu L, Buhot M-C, Daszuta A (1998): Differential effects of serotonin (5-HT) lesions and synthesis blockade on neuropeptide- $\mathrm{Y}$ immunoreactivity and $5-\mathrm{HT}_{1 \mathrm{~A}}$, $5-\mathrm{HT}_{1 \mathrm{~B} / 1 \mathrm{D}}$ and $5-\mathrm{HT}_{2 \mathrm{~A} / 2 \mathrm{C}}$ receptor binding sites in the rat cerebral cortex. Brain Res 795:264-276

Davis M, Gendelman DS, Tischler M, Gendelman PM (1982): A primary acoustic startle circuit: lesion and stimulation studies. J Neurosci 2:791-805

Davis M, Sheard MH (1976): p-Chloroamphetamine (PCA): Acute and chronic effects on habituation and sensitization of the acoustic startle response in rats. Eur J Pharmacol 35:261-273

Davis M, Cassella JV, Kehne JH (1988): Serotonin does not mediate anxiolytic effects of buspirone in the fearpotentiated startle paradigm: comparison with 8-OH-DPAT and ipsapirone. Psychopharmacol 94:14-20

Drescher K, Fink H, Langnickel R (1985): Neurochemical and behavioural effects after 5,7-DHT lesion of the median and dorsal raphe nucleus. Biogenic Amines 2:227-233

Dulawa SC, Hen R, Scearce-Levie K, Geyer MA (1997): Serotonin1B receptor modulation of startle reactivity, habituation, and prepulse inhibition in wild-type and serotonin1B knockout mice. Psychopharmacol 132:125134

Eison A.S, Eison MS, Stanley M, Riblet LA (1986): Serotonergic mechanisms in the behavioral effects of buspirone and gepirone. Pharmacol Biochem Behav 24:701-707

Fletcher PJ, Korth KM, Chambers JW (1999): Selective destruction of brain serotonin neurons by 5,7-dihydroxy- tryptamine increases responding for a conditioned reward. Psychopharmacol 147:291-299

Geyer MA, Braff DL (1987): Startle habituation and sensorimotor gating in schizophrenia and related animal models. Schizophr Bull 13:643-668

Geyer MA, Swerdlow NR, Mansbach RS, Braff DL (1990): Startle response models of sensorimotor gating and habituation deficits in schizophrenia. Brain Res Bull 25:485-498

Graham FK (1975): The more or less startling effect of weak prestimuli. Psychophysiol 12:238-248

Hensler JG, Kovachich GB, Frazer A (1991): A quantitative autoradiographic study of serotonin1A receptor regulation: Effects of 5,7-dihydroxytryptamine and antidepressant treatments. Neuropsychopharmacol 4:131-143

Hjorth S, Magnusson T (1988): The $5-\mathrm{HT}_{1 \mathrm{~A}}$ receptor agonist 8-OH-DPAT preferentially activates cell body 5 -HT autoreceptors in rat brain in vivo. Naunyn Schmiedeberg's Arch Pharmacol 338:463-471

Hjorth S, Sharp T (1991): Effect of the $5 \mathrm{HT}_{1 \mathrm{~A}}$ receptor agonist 8-OH-DPAT on the release of 5-HT in dorsal and median raphe-innervated rat brain regions as measured by in vivo microdialysis. Life Sci 48:1779-1786

Hoffman HS, Ison JR (1980): Reflex modification in the domain of startle: I. Some empirical findings and their implications for how the nervous system processes sensory input. Psych Rev 87:175-89

Kehne JH, Padich RA, McCloskey TC, Taylor VL, Schmidt CJ (1996): 5-HT modulation of auditory and visual sensorimotor gating: I. Effects of 5-HT releasers on sound and light prepulse inhibition in Wistar rats. Psychopharmacology 124:95-106

Koch M (1999): The neurobiology of startle. Prog Neurobiol 59:107-128

Koe BK, Weissman A (1966): p-Chlorophenylalanine: A specific depletor of brain serotonin. J Pharmacol Exper Ther 154:499-516

Lucki I (1992): 5-HT1 receptors and behavior. Neurosci Biobehav Rev 16:83-93

McGhie A, Chapman J (1961): Disorders of attention and perception in early schizophrenia. Brit J Med Psychol 34:103-116

Padich RA, McCloskey TC, Kehne JH (1996): 5-HT modulation of auditory and visual sensorimotor gating: II. Effects of 5- $\mathrm{HT}_{2 \mathrm{~A}}$ antagonist MDL 100,97 on disruption of sound and light prepulse inhibition produced by 5-HT agonist in Wistar rats. Psychopharmacol 124:107116

Pazos A, Palacios JM (1985): Quantitative autoradiographic mapping of serotonin receptors in the rat brain. I. Serotonin-1 receptors. Brain Res 346:205-230

Pompeiano M, Palacios JM, Mengod G (1992): Distribution and cellular localization of mRNA coding for 5-HT1A receptor in the rat brain: correlation with receptor binding. J Neurosci 12:440-453

Rigdon GC, Weatherspoon JK (1992): 5-Hydroxytryptamine1a receptor agonists block prepulse inhibition of acoustic startle reflex. J Pharmacol Exp Ther 263:486-493

Sipes TA, Geyer MA (1994): Multiple serotonin receptor subtypes modulate prepulse inhibition of the startle response. Neuropharmacol 33:441-448 
Sipes TA, Geyer MA (1995): 8-OH-DPAT disruption of prepulse inhibition in rats: reversal with (+) WAY 100, 135 and localization of site of action. Psychopharmacol $117: 41-48$

Sipes TA, Geyer MA (1997): DOI disrupts prepulse inhibition of startle in rats via 5-HT2A receptors in the ventral pallidum. Brain Res 761:97-104

Sprouse JS, Aghajanian GK (1987): Electrophysiological responses of serotonergic dorsal raphe neurons to $5-\mathrm{HT}_{1 \mathrm{~A}}$ and $5-\mathrm{HT}_{1 \mathrm{~B}}$ agonists. Synapse 1:3-9

Swerdlow NR, Geyer MA (1993): Prepulse inhibition of acoustic startle in rats after lesions of the pedunculopontine tegmental nucleus. Behav Neurosci 107:104-117

Swerdlow NR, Caine SB, Braff DL, Geyer MA (1992): The neural substrates of sensorimotor gating of the startle reflex: a review of recent findings and their implications. J Psychopharmacol 6:176-190

Swerdlow NR, Keith VA, Braff DL, Geyer MA (1991): Effects of spiperone, raclopride, SCH 23390 and clozapine on apomorphine inhibition of sensorimotor gating of the startle response in the rat. J Pharmacol Exp Ther 256:530-536

Van der Kar LD, Li Q, Cabrera TM, Brownfield MS, Battaglia G (1998): Alterations in 8-Hydroxy-2-(dipropylamino)tetralin-induced neuroendocrine responses after 5,7-dihydroxytryptamine-induced denervation of serotonergic neurons. J Pharm Exp Ther 286:256-262.

Yeomans JS, Frankland PW (1996): The acoustic startle reflex:neurons and connections. Brain Res Rev 21:301314 